\section{Eskimo Throwing-Sticks.}

I SEND you herewith a drawing of a throwing-stick which was brought to Washington by Captain John Rodgers, U.S.N., of the Vincennes, who explored the Behring and the Arctic Seas from I850-55.

In my paper on the " Throwing-Stick" (Rep. U.S. National Museum, I884, pl. vi.), this is figured as the Rodgers specimen, locality unknown. Subsequently, M. Adrien de Mortillet produced in the Revue Mensuelle de l'Ecole d'Anthropologie (viii. p. 246) a figure of a similar apparatus. Since then Mr. Walker Clark, of Edinburgh, Scotland, has sent me photographs of the same type from the Edinburgh Museum, and apparently associated with Beechey's explorations.

Dr. Franz Boas calls my attention to specimens of the same type in the American Museum in New York. The U.S. National Museum has also similar objects collected by Mr. Jas. G. Swan and the Rev. Vincent Colyer.

I have ascertained, by searching the records, that Captain Rodgers touched at Unalashka and collected specimens at that

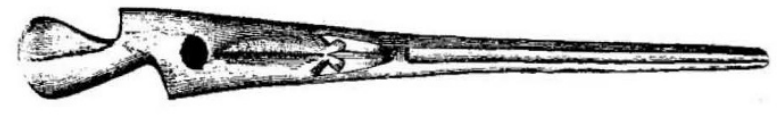

place belonging to Kadiak, Cook's Inlet, and Prince William's Sound. Putting all the information together it is now my opinion, confirmed by that of Dr. Boas, that all of these examples are from Prince William's Sound. This belief is confirmed also by the fact that these are the only Eskimo throwing-sticks which show carving in relief on the back. They seem to be all made of hard spruce, and by their markings to be allied to those of the more elaborately carved specimens from Sitka in the British Museum, the United States National Museum, and elsewhere. The front or top side of the specimen has a fine ivory point for the butt end of a delicate sea otter, barbed harpoon, and a shallow groove only half its length. The finger pocket does not extend quite through to the top side.

U.S. National Museum, Washington, June 25. TIS T. MASON.

The Salaries of Science Demonstrators.

THE enclosed fable, possibly from a missing edition of Kingsley's "Water Babies," seems to have some remote connection with the heading that has been affixed to it. O. J. L.

An aggrieved tadpole once found its way as a deputation to Mother Carey, and complained as follows, at first reading from a document, but afterwards becoming more eloquent and expressive :-

"We, your industrious and not unworthy subjects, desire to lay before you our wrongs. We cannot get out on to the land and attend meetings as the frogs do, and consequently we get no flies; yet it.is we who do all the work of the pond. The frog only looks in now and then; and even if he had a mastermind (which he hasn't), his visits would have no effect. $\mathrm{He}$ croaks, that's what he does; he sits on the bank and eats flies, and he croaks, and so he gets listened to. As for us, we are treated no better than sticklebacks or minnows; why, there's a bloated travelling newt, who gets twice as much as we do. It's all because you old fogies are accustomed to croak yourselves. It's all___ "

"And what prospects have the minnows and sticklebacks?" here interrupted the dame. "When do they hope to leave the pond and gain advancement?"

"Why, never, of course ; they've got all they'll ever get, and too much at that," grumbled the tadpole.

"And do you also intend to remain in your present condition always?"

"Not I : I intend to become a frog, and hop about, and attend meetings, and catch flies, and make a noise in the world."

"Yes; and, meanwhile, you would like these desirable appurtenances of the frog state diminished? Remember your whole pond is but a recently banked-up affair-on rather NO. I 395 , VOL. 54] sandy soil, and the margin is narrow; it might run empty unexpectedly, you know."

"I don't care," ejaculated the tadpole; "cut off the water, and then we shall all be on dry land together; anything better than the present inequality."

"Very well," said the dame; "I know some creatures in a state of probation, not long out of the egg, who actually have to pay for the privilege of practising their future career. However, your wish that one of the recently.dug supply channels shall be stopped, so that your pond may run dry enough to let you also touch solid land as your predecessors have otherwise done, is so simple and easy to carry out, that perhaps it can be managed. Fare thee well."

\section{A Curious Rainbow.}

WHILST enjoying a general survey of the sky this evening I was giving my attention more particularly to an expanse of brilliantly white cirrus cloud, unusually complicated in its detail, when, at 7 p.m., a small inverted rainbow suddenly became apparent along the front margin of this cloud (now approaching the zenith from W.S.W.).

The bow, at first, just spanned the width of the cloud upon which it was projected, but as it increased its length a little at its "left," or south-western extremity, and as the cloud drifted slightly to "right," or north of eastwards, the bow was at last wholly projected upon a background of (apparently) clear blue sky. This last effect was extremely beautiful ; the bow being so brilliantly coloured that it would, I think, hardly have escaped my notice, even if I had not first seen it upon the background of white cloud.

There was a perfect sequence of all the prismatic colours from the red, below, to the violet, above-and the curvature of the bow was remarkably rapid - and extending not more than about $2^{\circ}$ in length.

It remained visible for about 5 or 7 minutes.

If any one can furnish me, through the medium of your columns, with an explanation of this peculiarly beautiful phenomenon, and in language that can be " understanded of the people," I shall be greatly obliged.

Barnet, July. I2.

\section{Effect of Lightning.}

ON Tuesday, July 7, a violent storm passed over this district, and three balls of fire have been reported. Two trees were splintered, and two sheep were struck by lightning on the downs.

One sheep was not seriously injured, but the other was killed; on being struck, both sheep turned over on their backs. The one fatally injured was struck on the top of the head, the lightning passing down the animal's right jaw on to its breast here it divided into three, and passed down both fore-legs and under the stomach. The course of the lightning on the wool was like the track of a red-hot poker. After death the aft part and belly of the sheep were greatly distended, as if with air. The blood appeared to have rushed from the head to the rear of the animal at the moment of death, for, on skinning the sheep, the neck part was found to be destitute of blood, whilst a considerable amount of blood was under the skin of the back, as if blood had escaped to that position. The sheep's mouth was disterted by being drawn aside. Close to the sheep's fore-feet a hole was made in the ground by the lightning, about the size of a quart jug.

Dunstable. WORTHINGTON G. SMITH.

\section{A Brilliant Meteor.}

I HAD the pleasure on Friday evening last, the 16 th inst., of observing a brilliant meteor from a point about half-way between the towns of Blaenau and Llan Festiniog. The time was 9.10 p.m., the sky quite clear, and not dark enough for any stars to appear. The meteor appeared almost due south of my position, the length of its path being an arc of about $20^{\circ}$, disappearing a short distance above the horizon, and lasting about four secon ds. Very little trail could be seen, as it was practically daylight. The colour appeared of a bluish tinge, and the meteor appeared to become brighter in the middle of its path.

\section{H. H. WAI.Ker.}

County School, Blaenau Festiniog, July I9. 